University of Windsor

Scholarship at UWindsor

\title{
The Use of Argument Maps as an Assessment Tool in Higher Education
}

Chrysi Rapanta

ArgLab, Institute of Philosophy, Universidade Nova de Lisboa (IFILNOVA), Lisbon, Portugal

Douglas Walton

University of Windsor, Centre for Research in Reasoning, Argumentation and Rhetoric

Follow this and additional works at: https://scholar.uwindsor.ca/crrarpub

Part of the Arts and Humanities Commons

\section{Recommended Citation}

Rapanta, Chrysi and Walton, Douglas. (2016). The Use of Argument Maps as an Assessment Tool in Higher Education. International Journal of Educational Research, 1-11.

https://scholar.uwindsor.ca/crrarpub/37

This Article is brought to you for free and open access by the Centre for Research in Reasoning, Argumentation and Rhetoric (CRRAR) at Scholarship at UWindsor. It has been accepted for inclusion in CRRAR Publications by an authorized administrator of Scholarship at UWindsor. For more information, please contact scholarship@uwindsor.ca. 


\title{
The Use of Argument Maps as an Assessment Tool in Higher Education
}

\author{
Chrysi Rapanta ${ }^{\mathrm{a}, *}$, Douglas Walton ${ }^{\mathrm{b}}$ \\ a ArgLab, Institute of Philosophy, Universidade Nova de Lisboa (IFILNOVA), Lisbon, Portugal \\ ${ }^{\mathrm{b}}$ Centre for Research in Reasoning, Argumentation, and Rhetoric (CRRAR), Windsor, Ontario, Canada
}

\section{A R T I C L E I N F O}

\section{Article history:}

Received 19 January 2016

Received in revised form 29 February 2016

Accepted 7 March 2016

Available online $\mathrm{xxx}$

\section{Keywords:}

Argumentation theory

Artificial intelligence

Argument maps

Diagramming tools

Assessment

Fallacies

Education

\begin{abstract}
A B S T R A C T
The use of argument diagrams to foster argumentation has been an object of research in education, as a way to support students' argumentative interaction and, potentially, learning. In this paper it is shown how argument analysis and evaluation assisted by means of argument diagramming tools, further developed in artificial intelligence (AI), can also support the assessment of argumentation skills in the classroom. A case study is presented to show how informal logic contributions on fallacies, in particular, can be combined with the data of an argument-diagramming task, to form a method of assessing students' weaknesses in reasoning about everyday issues using argument maps. Our contribution is mainly methodological, as we suggest an application of AI and argumentation theories in education.
\end{abstract}

(c) 2016 Elsevier Ltd. All rights reserved.

\section{Introduction}

Argument-mapping tools are designed to help a user visualize the premises and conclusions of arguments in a graph structure, and display a sequence of connected arguments chained together to support an ultimate conclusion. More than fifty computational argument-mapping tools that can be used to assist an argument analyst are described by Scheuer, Loll, Pinkwart, and McLaren (2010).

Empirical research has shown that argument mapping is a useful learning and teaching methodology, mainly because of the importance of making reasoning explicit in different learning situations (Dwyer, Hogan, \& Stewart, 2013; Maloney \& Simon, 2006; Scheuer, McLaren, Weinberger \& Niebhur, 2014; van Amelsvoort, Andriessen, \& Kanselaar, 2007). For instance, argumentative interactions have an important place in collaborative learning, as students tend to make their arguments explicit and to change their premises as a result of their peers when reasoning together to solve a problem (Asterhan \& Schwarz, 2009; Baker, 2009). But also in individual learning situations, either oral or written, students commonly use theories and explanations supported by evidence when faced with complex cognitive subjects (e.g. Berland \& Reiser, 2009; Toth, Suthers, \& Lesgold, 2002). More recently, computer-mediated argumentation in dyads or small groups of students using some type of chatting platform has also been the focus of research (Andriessen, Erkens, van de Laak, Peters, \& Coirier, 2003; Kuhn, Goh, Iordanou \& Schaenfield, 2008). In all these cases, teachers need to be able to assess student-generated arguments, distinguish them from other reasoning elements, e.g. explanations, and suggest ways for their improvement.

\footnotetext{
* Corresponding author.

E-mail address: crapanta@fcsh.unl.pt (C. Rapanta).
} 
Although argument maps have been broadly used as a way to support students' argumentation, through making their premises explicit, no evidence exists yet on the function of such tools for assessment purposes.

This paper presents a way of assessing students' argumentative reasoning through looking at their argument maps. To do that, we combined the use of an online argument-mapping tool called Rationale with the application of the recent theory of paraschemes (Walton, 2011a). The result of this "marriage" is a proposal of a thorough pedagogical assessment in the field of argument and education, as presented below.

This proposal may have a series of practical implications for educators at various levels, especially for the ones working with adolescents and young adults. The reason lies on the function of active argumentative writing from part of the students and the instructor-guided argument reconstruction that needs to take place for such writing to improve. The use of argument structuring and visualization processes in educational argumentation contexts has been widely used, as described in the next section. However, it is still unclear how the structured reconstruction of arguments by students using argument maps can be of further use for reasoning assessment and improvement purposes.

\section{State of the Art}

\subsection{Argument mapping tools and education}

The use of argument diagramming tools in education is a way to represent students' arguments in dyads, groups, or individually. It is explained by the two-dimensional format of such diagrams in which students can visualize their reasoning with boxes for premises and conclusions, and pro and con arrows for arguments. "This kind of representation is thought to support argumentation because visualizing an argument stimulates users to include evidential relations, to keep a balance between pro and contra arguments, to relate arguments and see inconsistencies and conflicts" (Munneke, Andriessen, Kanselaar, \& Kirschner, 2007, p. 1076-1077).

In practice, the issue of whether use of argument mapping tools helps either individual or collaborative learning is controversial, as the findings of previous research are mixed. Some studies suggest that argument diagramming is helpful while others find little or no learning increment. One such experimental study (Pinkwart, Lynch, Ashley, \& Aleven, 2008) used LARGO, an information technology system for legal argumentation that helps students to build argument diagrams to model the argumentation found in transcripts of US Supreme Court oral arguments. It was found that using Largo did not lead to superior learning as compared to a text-based note-taking tool. However, it was also found that use of the system could help lower-aptitude students. Other studies suggest a general connection between argument mapping and enhancement of critical thinking skills (e.g. Twardy, 2004; van Gelder, 2005) without concrete evidence on how students' arguments, argumentation dialogues, and learning outcomes are changed as a result of the mapping. Regarding the influence of diagrams and maps on argumentative interactions, Suthers (2003) found no significant influence on the depth of the interaction, whereas Munneke et al. (2007) described the argumentative activity taking place as result of a diagramming scaffold as "not really interactive" (p. 1086).

Nonetheless, argument maps have also been considered as useful scaffolds for critical thinking and writing. For instance, Okada and Buckingham Shum (2008) showed that the structuring and modeling provided by an argument map is helpful for science education, especially when it concerns evidence-based writing. Other researchers claim that the pedagogical function of maps increases when combined with other scaffolds. Marttunen and Laurinen (2007), for example, have found that secondary school students produce better argument maps by engaging in debate, as they become better acquainted with the diversity of viewpoints about the topic at hand. Following a similar approach, Scheuer et al. (2014) combined argument mapping with collaboration scripts that guide the student discussants through the process of analyzing and evaluating opposing positions on a contentious topic to help all parties to the discussion move forward towards the goal of collaboratively generating a well-reasoned conclusion.

All the above examples of use of argument mapping tools in education face the same challenge or lack: their use is limited to an intervention or scaffolding level without any explicit connection to the assessment of the arguments produced from an informal logic perspective. Most of the efforts provide a straightforward assessment of the students maps based on the quantity of the boxes completed. New computational argumentation systems developed in artificial intelligence have gone even further to support both argument evaluation and argument construction (Gordon, Prakken, \& Walton, 2007; Gordon, 2010; Reed \& Rowe, 2004; Reed, Walton, \& Macagno, 2007). For example, the Carneades Argumentation System (CAS http:// carneades.github.com/), named after the Greek skeptical philosopher, can both evaluate given arguments and construct (invent) new ones. A CAS argument graph is a bipartite, directed, labeled graph, consisting of statement nodes and argument nodes connected by premise and conclusion edges. CAS is a formal argument structure where argument graphs are evaluated, relative to audiences, to determine the acceptability of statements in a stage (Gordon, 2010). Conflicts between pro and con arguments are resolved using proof standards, such as preponderance of the evidence and clear and convincing evidence, inspired by the legal domain. CAS supports argument construction by generating new arguments automatically from a knowledge base of rules and facts.

In general, educational research that includes argument maps focuses on the use of specific diagramming tools either alone or in combination with other tools (e.g. scripts, chatting) as part of an intervention to enhance either arguments themselves or learning of scientific concepts (following the generally known distinction between "arguing to learn" and "learning to argue"). The recently proven value of argument maps as diagnostic methods of analysis and assessment has not 
yet been integrated in the educational field. On the other hand, more and more educational researchers are interested in the task of identifying and assessing flaws or fallacies in students' argumentative performance (e.g. Neuman, 2003; Osana \& Seymour, 2004; Weinstock, Neuman, \& Glassner, 2006), without providing opportunities for reconstruction of the fallacious reasoning. Some of the most common flaws among adolescents and adults in terms of their argumentative reasoning are: the lack of distinction between justification and explanation (Brem \& Rips, 2000), the lack of consideration of the other party (Glassner \& Schwarz, 2007), and the weakness to produce strong rebuttals, e.g. answers to counter-arguments (Kuhn et al., 2008). Argument maps can give students and teachers the opportunity to localize and reconstruct argument flaws, as they provide a complete, two-sided argument structure, easy to understand and use. What is still missing is the method employed by researchers and/or educators to assess the arguments produced as more or less flawed and to provide the steps for their reconstruction.

Our work endeavors to fill in this gap by presenting a case study showing how to identify fallacies from the data produced in a simple argument-mapping task. To do this, we implemented the recent theory of paraschemes, which is described in detail below. In comparison to other theories of fallacies, the paraschemes approach is much more than a classical logical evaluation of logically good or bad arguments. It gives an overview on how weak an argument is in a given context, pointing out that the speaker has overlooked some crucial contextual aspects, such as relevant knowledge sources on which to base his/her point of view, or core counter-arguments against his/her viewpoint. On this view, a crucial dimension of argument assessment consists in determining whether the speaker has taken into account all the aspects and components of an argument, without "overlooking" fundamental contextual premises. This approach to argument assessment and reconstruction is crucial in higher education teaching and learning, as most one of the main reasons that prevents adults from thinking thoroughly and consistently is the so-called intellectual laziness (Goodwin, 2010), which also lies behind most heuristic thinking (Klaczynski, 2001). Implementing a method that defines arguments as having two sides, i.e. the systematic one and the less critical (or more "context-overlooking") one, is thus important for any educational context.

\subsection{Paraschemes as a method for identifying fallacies}

For the reasons explained above, the approach to fallacies in this paper depends on the concept of a parascheme, as defined in terms of the widely known concept of a heuristic (Walton, 2010, p. 160). According to dual-processor theories in cognitive science, there are two systems that can be employed to arrive at a conclusion. In the rule-based, controlled and conscious system of reasoning, careful calculations are used to arrive at a conclusion. The other system is based on heuristics, rapid inferences that apply to situations that are familiar, enabling a fast decision to be made under conditions where there is insufficient time to plan carefully collect evidence (Gigerenzer, Todd, \& The ABC Research Group, 1999). Heuristics are useful in reaching a decision under constraints of lack of time and complete knowledge. As long as they are seen as tentative, heuristics can be a good way of arriving at a tentative conclusion, subject to later correction as new evidence comes in. But the problem is that we sometimes apply them inappropriately in place of collecting new evidence, or even refuse to reject a conclusion arrived at on the basis of heuristics, even when new evidence has come in showing that the conclusion ought to be questioned or even rejected.

In the account given by Walton (2010), the heuristic is a mediating concept between the notion of fallacy and the notion of a defeasible argumentation scheme. If an arguer jumps too quickly to a conclusion, and later on fails to retract that conclusion even if new evidence has come in makes the inference to it unwarranted. This situation is characteristic of many instances of informal fallacies. For example the heuristic for argument from expert opinion can be concisely expressed as follows:

if $p$ is an expert opinion, $p$ should be accepted (is likely to be true).

Obviously, this heuristic is comparable to the argumentation scheme for the argument from expert opinion, but it is only a short "quick and dirty" reasoning version of it that overlooks other qualifications that may need to be applied for the scheme to be valid. For example we may need to ask what field the expert is supposed to be qualified in, or whether the expert has evidence to back up his or her claim. On this approach, the fallacy of ad verecundiam, the incorrect use of argument from expert opinion, is committed when the arguer uses this form of argument but overlooks critical questions, qualifications and counterarguments that need to be taken into account. The complete form of an argument from expert opinion accompanied by some critical questions to ask, in order to judge its completeness and validity, is described by the following scheme (Walton, Reed, \& Macagno, 2008, p. 310):

Major Premise: Source E is an expert in subject domain $\mathrm{S}$ containing proposition A.

Minor Premise: E asserts that proposition A is true (false).

Conclusion: A is true (false).

Expertise Question: How credible is $\mathrm{E}$ as an expert source?

Field Question: Is $\mathrm{E}$ an expert in the field $\mathrm{F}$ that $\mathrm{A}$ is in?

Opinion Question: What did E assert that implies A?

Trustworthiness Question: Is E personally reliable as a source?

Consistency Question: Is A consistent with what other experts assert?

Backup Evidence Question: Is E's assertion based on evidence? 


\section{Method}

The goal of this study is to show how an easy-to-use argument mapping tool, such as Rationale (van Gelder, 2007), in combination with a recently developed informal logic method of identifying paraschemes can serve as a diagnostic tool of heuristic reasoning emerged among students in higher education. On the one hand, paraschemes serve as a more realistic way of assessing students' arguments, based on criteria that are structured and context-related, and not on mere classifications of "wrong" argument patterns. On the other hand, argument maps are essential for reconstructing the missing premises, the contextual information, and thus provide answers to the critical questions. Through identifying and visualizing what is wrong or missing in their reasoning, students have more chances to understand it and improve it. In addition, it is important that teachers of all levels, especially in higher education, guide students in improving their informal logic skills in concrete and understandable ways.

To better show off our methodological proposal, we opted for the case study method. According to Yin (1994), one of the applications of the case study is also to describe the intervention itself. As explained above our data come from two different samples, one in Europe (Spain) and another in Asia (Middle East). The goal of the study is not to multiply the findings by cross-matching observations in the two samples. From this point of view, our study is a not a multiple case study. We do use, however, the two ethnically different samples as two "contexts of use", which is another way to increase the internal validity of a case study design (Danziger, 1985). In the end, what we expect is some type of "naturalistic" generalization, as termed by Stake (1995), in the sense that what we will hereby present in terms of design and method used can "resonate experientially with a broad cross section of readers" (Tellis, 1997), in our case, educational researchers and practitioners.

\subsection{Participants}

In total, 205 University students participated in the study; of them, 112 were undergraduates at a University in Dubai, United Arab Emirates (U.A.E.), whereas 93 were undergraduates at a University in Barcelona, Spain. The sample was mixed regarding gender (58 males and 147 females) and discipline (Business and Education), and the average age was 19.5 years old.

\subsection{Design}

Participants were chosen according to classroom. In total, there were 5 Emirati classes and 3 Spanish classes. All of them were taught materials for which argumentation was of great relevance but none of them had received formal instruction on argumentative reasoning before. The procedure was the following for all participant classes: the same instructor gave a 45minute seminar on the basics of argumentation skills; after that, the students had 15-20 minutes to complete the argument map presented in Fig. 1 as extracted from the Rationale tool interface.

The map consists of seven bubbles or map nodes: the beginning one or contention, which belongs to the initial claim, three bubbles on the left where all reasons supporting the claim are to be written, and three bubbles on the right part, being the counter-argument, i.e. what the other party would object, one reason supporting the objection, and a rebuttal that reestablishes the truth of the initial claim. Students were informed that all the steps of this mapped reasoning starting from the left and finishing on the right are important and necessary. Regarding the initial claims or "topics" of their argumentation,

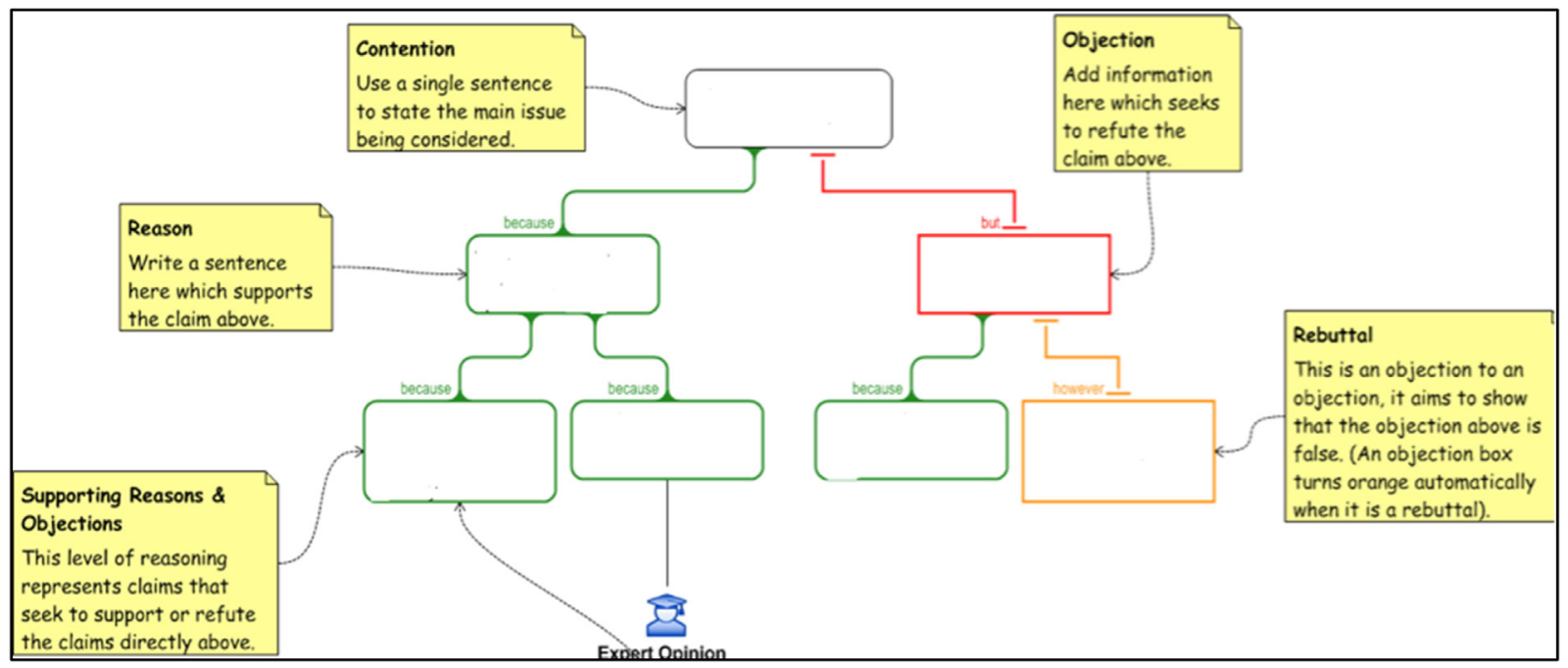

Fig. 1. The Argument Map Task (extracted from Rationale Tool (van Gelder, 2007)). 
some ready examples of everyday reasoning were given to them. However, all participants could choose their own initial contention if they wanted to. These were the three given topics to choose from:

1. Employees should not for any reason bring their pets to the workplace.

2. No person is allowed to stay at office during the night.

3. We should apply a more environment-friendly policy.

\subsection{Assessment}

As defined by the map task, there are six argument units to be assessed: one main reason for the claim, two supporting reasons, one objection, one reason for the objection, and one rebuttal. In most instances, the contention or initial claim given to the participants, so it did not form part of the assessment. What we are interested in is the skill to dialectically support a statement without being in an actual dialogue. In this case, fallacies related to pragmatic conditions of a real dialogue do not naturally emerge. For instance, we cannot produce an ad hominem argument when we argue alone. For similar reasons, the skill to argue in individual tasks requires for the ability broadly defined as antilogos, i.e. the ability to critically evaluate whether specific information may support different claims (Glassner \& Schwarz, 2007). The lack of manifestation of this ability, which is shown to relate to predominance of heuristic thinking among adolescents and adults (Glassner \& Schwarz,

Table 1

Main Informal Argumentation Schemes and their Corresponding Fallacies.

\begin{tabular}{|c|c|}
\hline Argumentation scheme & Critical questions \\
\hline From popularity: Nearly everyone accepts A, so presume that A is true or right. & $\begin{array}{l}\text { Q1: Is it relevant for the specific context that people } \\
\text { believe or do A? }\end{array}$ \\
\hline Corresponding fallacy: Ad populum & $\begin{array}{l}\text { Q2: Are there enough reasons to believe or do A? } \\
\text { Q3: Are there any reasons not to believe or do A? }\end{array}$ \\
\hline Gradualism: If you take step A, you will eventually fall into bad consequences. & $\begin{array}{l}\text { Q1: Is there a strong relation between } \mathrm{A} \text { and its } \\
\text { consequences? }\end{array}$ \\
\hline Corresponding fallacy: Slippery slope & $\begin{array}{l}\text { Q2: Is there enough evidence that A will eventually lead } \\
\text { to these consequences? } \\
\text { Q3: Is there a way that bad consequences can be } \\
\text { avoided? }\end{array}$ \\
\hline
\end{tabular}

From consequences: If $\mathrm{A}$ is brought about, then good (or bad) consequences will occur. Therefore, do (or do not) A.

Corresponding fallacy: Ad consequentiam

From ignorance: All the true propositions of domain $\mathrm{D}$ in knowledge are contained in $\mathrm{K}$. A is not in K. Therefore, A is false.

Corresponding fallacy: Ad ignorantiam

From expert opinion: An expert says that $\mathrm{A}$ is true in their domain of expertise. Therefore, $\mathrm{A}$ is true.

Corresponding fallacy: Ad verecundiam

From correlation to cause: There is a correlation between A and B, therefore A causes B.

Corresponding fallacy: Post hoc

From a group of cases to a generalization: Case 1 (C1) is considered representative of a group of cases (G). C1 has a characteristic A. Therefore, all the cases of $\mathrm{G}$ are considered to have A. Corresponding fallacy: Hasty generalization

From analogy: One case (C1) is similar to another (C2). A is true in C1, therefore it is true in C2. Corresponding fallacy: False analogy

\section{Q1: same as above}

Q2: same as above

Q3: Are there other reasons rather than A that can have the same consequences?

Q1: Is it true that all $\mathrm{D}$ are in $\mathrm{K}$ ?

Q2: Is there enough evidence to believe that $\mathrm{A}$ is not in $\mathrm{K}$ ? Q3: Are there any other reasons for believing A without it being part of $\mathrm{K}$ ?

Q1: Is $\mathrm{E}$ an expert in the field $\mathrm{F}$ that $\mathrm{A}$ is in?

Q2: What did E assert that implies A?

Q3: Is E's assertion based on evidence?

Q1: Is there a large enough number of instances in which A correlates with B?

Q2: Do other variables other than A correlate with B?

Q3: Can B exist also without A?

Q1: Is the generalization justified in terms of how known or representative $\mathrm{C} 1$ is?

Q2: Do the other cases that belong to $G$ have additional characteristics that do not imply A?

Q3: Can there be any exceptions to the rule that all cases of $G$ have $A$ ?

Q1: Are C1 and C2 similar in respects cited?

Q2: Is A true in C1?

Q3: Are there differences between $\mathrm{C} 1$ and $\mathrm{C} 2$ that undermine the force of the similarity? 
2007; Klaczynski, 2001), leads to a list of reasoning flaws, which call for their identification and assessment. On the contrary, a full consideration of critical questions-limitations, which reflect common ways of defeating a particular type of argument (Nussbaum, 2011), leads to plausible argumentation schemes, some of which are presented on Table 1 (for a comprehensive list of schemes see Walton et al., 2008). Each argumentation scheme provides reasons (premises) to believe a claim, but the reasons can be weakened if one of the corresponding critical questions is not sufficiently answered by the analyst on the basis of the argumentative reasoning data. In this case the valid argumentation scheme may become a parascheme, or a corresponding fallacy, as shown in Table 1.

We herewith present the steps we followed during our analysis of the six argumentative units. At this point a clarification needs to be made. Even though the physical dialectical partner is not present, we can still assume that intrapersonal argumentative reasoning is divided into four levels: (1) the first level of justification, where reasons relate to their claims, (2) the second level of justification, where reasons relate to each other, (3) the first level of counter-argumentation, where the objection is judged against the claim, and (4) the second level of counter-argumentation, where the rebuttal is judged against the objection and against the initial claim. We can also say that claims, reasons, and rebuttals "belong" to the proponent's side, whereas objections and reasons for objections belong to the opponent's side. Having said that, here is the rationale of our analysis divided into five steps. Each step applies to the analysis of each one of the six argumentative discourse units per map.

\section{Step one}

The first step is to identify arguments by looking for keywords that may relate to one argument scheme more than to others. According to Walton (2011b), each scheme is associated with a set of identifiers - keywords and markers. Table 2 presents the main argumentation schemes discussed in Table 1 with some examples of relevant keywords for each.

\section{Step two}

Once the argumentation scheme is identified, the second step it to ask the three main critical questions that apply for each scheme. Sometimes, the answers to the critical questions can be found in further steps of the person's reasoning, such as in the objection or the rebuttal. See, for example, the following instance of a possible ad verecundiam fallacy:

Claim: We shouldn't have cats as pets at home.

Reason 1: Doctors say they create problems for women.

Reason 2: Many women had cats and when they got married they couldn't give birth.

Reason 3: Cats can introduce diseases to a woman's skin.

Objection: Doctors sometimes say something without proving it.

This objection can be reconfigured as a critical question matching the scheme for argument from expert opinion, and another critical question matching this scheme can also be considered. How objections can arise in such a case, and how they relate to argumentation schemes and critical questions can be illustrated using the argument diagram shown in Fig. 2. The explicit premises are shown as rectangular text boxes. The arguments are shown as rounded nodes that contain some information about the argument. For example, at the top right, the statement that cats can introduce disease to a woman's skin is shown as a premise in argument a2 supporting the ultimate conclusion. The plus sign before a2 in the node tells us that this is a pro argument. A pro argument is one supporting its conclusion, while a con argument is one attacking the statement or argument is directed against. Notice also that one of the arguments is labeled as a pro argument from expert opinion, indicated by the notation ex in the node. The explicit premise of this argument is the statement that doctors say cats create problems for women. But in order to make this argument fit the argumentation scheme for argument from expert opinion and implicit premise has to be inserted, namely the statement that doctors are experts in such matters. And implicit premise is indicated by the dashed borderline of the rectangle of the text box.

Note that in the argument labeled a1, both of the premises are implicit, and these two implicit premises in the linked argument a1 fit the argumentation scheme for defeasible modus ponens. In many instances, when unlinked argument cannot be found to fit any other scheme, it can be fitted to the defeasible modus ponens form, often by adding an implicit conditional premise.

Table 2

Main Keywords that Help to Identify Argumentation Schemes.

\begin{tabular}{ll}
\hline Argumentation scheme & Related keywords \\
\hline From popularity & (Many/most) people think/prefer/believe/do that \\
Gradualism & Something will/would be worse than before \\
From consequence & Something will bring benefits or bad consequences \\
From ignorance & I do not know any .../to my knowledge there is no ... \\
From expert opinion & Experts/Doctors/scientists/Mr. (surname)/Ms. (surname) say/claim/have found that \\
From correlation to cause & Something is happening or will happen due to its relation to a previous state \\
From generalization & One person/case/myself does/is like that \\
& OR All people/cases are like that \\
From analogy & Same as above (the first case), but with the intention to provide an example that is offered as basis for comparison \\
\hline
\end{tabular}




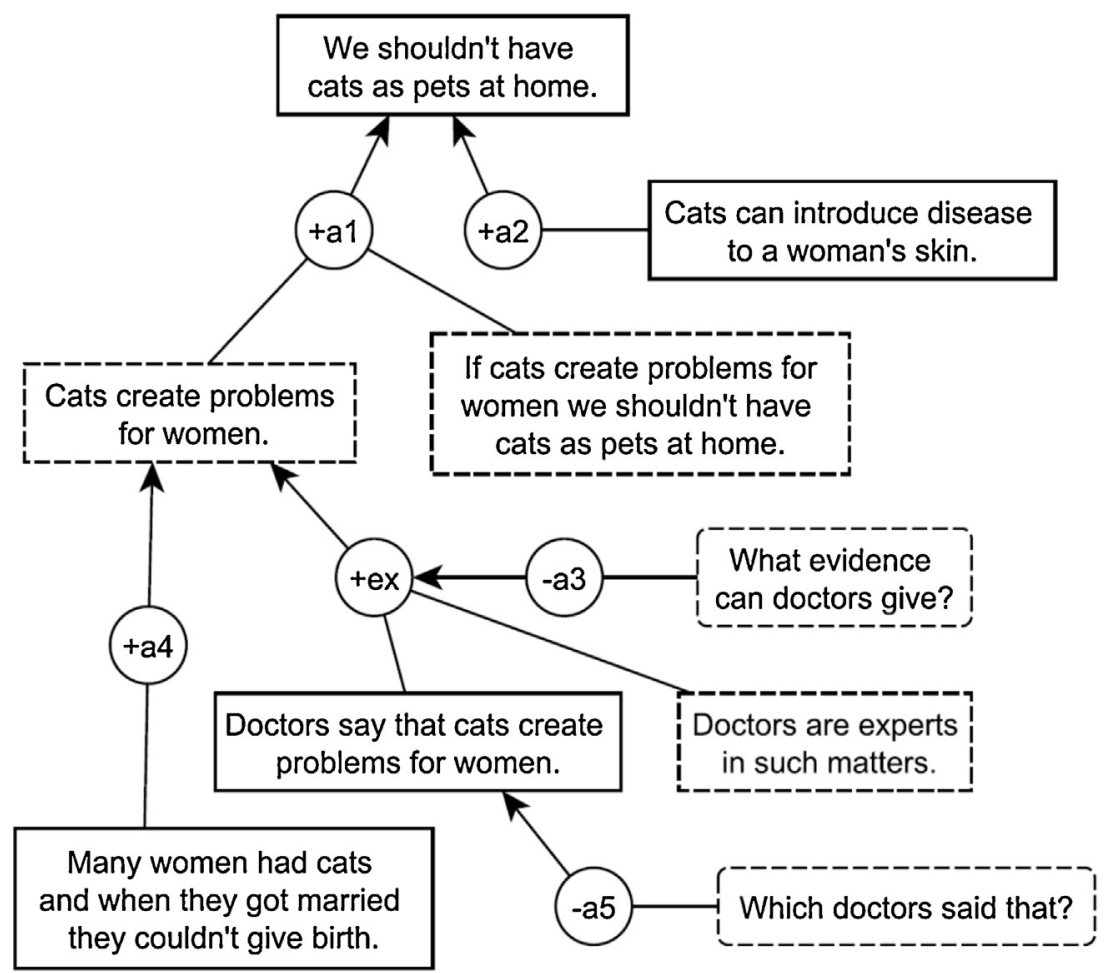

Fig. 2. An Argument Diagram for the Cats Example.

The critical questions are shown in Fig. 2 in rectangular text boxes with rounded corners and dashed lines. What has been done here is to adopt the method of treating the critical questions as con arguments. Notice that the one critical question is treated differently from the other. The critical question shown as con argument a5 asks the arguer to provide the names of some doctors who have said that cats create problems for women. This critical question is shown as a con argument that attacks the one premise of the argument from expert opinion, namely the statement that doctors say that cats create problems for women. The other critical question matching the scheme for the argument from expert opinion, shown as argument a3, is modeled as an undercutter, meaning that it attacks the inferential link of the argument from expert opinion. Unless the arguer supporting the ultimate claim can give some evidence of this kind, the argument from expert opinion will fail.

The first reason given to support the main claim is not sufficient by its own: doctors say that cats create problems for women. However, critical question 2 regarding the specific aspects of the expert opinion is sufficiently replied through reasons 2 and 3. Then, we have Q1 regarding the credibility of the doctor and Q3 regarding concrete evidence. These questions are not sufficiently replied to in the first part of argumentation when the participant supports her own opinion. Nonetheless, when we move to the second part of the map when one counter-argues against herself, we see that the objection is completely relevant to the lack of evidence and credibility concerning the statement that doctors sometimes say something without proving. This statement implies that the arguer has awareness of the argumentative quality and he knows exactly what to put under doubt. For this reason, we consider the above argument as an instance of the scheme of argument from expert opinion rather than a parascheme that gives rise to an ad verecundiam fallacy.

Table 3

Criteria to Distinguish between the Ad Populum and the Hasty Generalization Schemes.

\begin{tabular}{ll}
\hline Scheme & From popularity or ad populum \\
\hline Criteria & $\begin{array}{l}\text { Reference to people is used to give credibility to a situation. } \\
\text { It usually refers to people's beliefs, tendencies, or pReferences. } \\
\text { It is a vague reference to the crowd. }\end{array}$ \\
\hline Scheme & From (hasty) generalization \\
\hline Criteria & $\begin{array}{l}\text { It is often used to compare one situation to another and give more credibility to one of them. } \\
\text { It usually refers to people's actions. } \\
\text { It refers to a known number of people/cases. }\end{array}$ \\
\hline
\end{tabular}


Step three

Sometimes we do not have enough information to immediately classify an argument as fitting one type of argument scheme/parascheme or another. In this case, some additional critical questions need to be asked. Here is an example of an argument that was problematic to classify:

Claim: Employees should not for any reason bring their pets to the workplace.

Objection: They will create a nice environment.

Reason: Many people like pets.

In the example above, the possible fallacy appears within the reason that is given to support an objection. In this case no additional reasons or further support are given, thus critical questions cannot be answered sufficiently. For this reason, it can be assumed that the above scheme corresponds to a fallacy. Among the fallacies presented on Table 2, two are most appropriate to be the case here: ad populum or hasty generalization. Table 3 shows a way of how to distinguish between the two possibilities based on criteria that better correspond to one scheme than to another.

In our example, there is no intention of comparison of a situation that is more generally acceptable than another, as it would be in the case of generalization. Also the statement "Many people like pets" expresses a general preference not attributed to a concrete number of cases. Thus, it is more suitable to classify the argument as an ad populum fallacy rather than as a hasty generalization.

Another example of distinction is the one between an argument from an expert opinion and an argument from an established rule (Walton et al., 2008), especially in the cases when the established rule is presented as imposed by an authority to which no one can object. The following instance is an argumentation example produced by an Emirati female participant:

Claim: University female students should not get married while studying.

Reason 1: Marriage is a responsibility that requires time and priorities therefore they will fail in each course.

Reason 2: A human being cannot multi-task properly therefore they will fail in either education or marriage.

Reason 3: A University student can wait to get married for a better academic performance.

Objection: Our community sets rules that it is very OK to get married at that age and you cannot say no to that.

Reason: The University can manage to have a light schedule for married women.

Rebuttal: UAE community is growing and changing their age of marriage.

The argument from established opinion lies in the objection that the local community sets rules according to which marriage at an early age is not only allowed but also desired. The institution behind the rule establishment, in this case the "community," is very similar to an authority whose word should be respected regardless what. However, an argument from expert opinion would start by something like "Experts say", "Doctors say", or "Mr./Ms. X says." Here is an example:

Claim: Employees should not for any reason bring their pets at work.

Reason 1: It is non-hygienic.

Reason 2: Experts say that they provoke distraction and reduction in performance.

Reason 3: They make noise.

This argument fails to give a satisfying answer to all three corresponding critical questions, as they appear on Table 1 . First of all, the word "experts" is very general and does not reveal anything of the type of expert or field of study. No expert is even named. Secondly, the experts' statement on distraction and performance reduction is again general and poorly justified by the simple observation that pets make noise. Last but not least, no concrete evidence is provided. For all these reasons, the argument is considered a parascheme or ad verecundiam fallacy. To distinguish this (para) scheme from the (para) scheme of an argument from an established rule, the following three additional critical questions should be asked: (1) Is the statement made by an expert or by a general body, institution, or commonly accepted view? (2) Does the statement refer to a rule about how things should be or to a body of knowledge and/or experience? (3) Does the extra evidence concern the credibility of the source or the general acceptance of the statement? Table 4 presents the distinctive criteria between an argument from expert opinion and an argument from established rule:

Table 4

Criteria to Distinguish between the Argument from Expert Opinion and From Established Rule.

\begin{tabular}{ll}
\hline Scheme & From expert opinion/ad verecundiam \\
\hline Criteria & $\begin{array}{l}\text { The source is an expert, either a specific person or a body of experts in a particular field. } \\
\text { The statement refers to a particular piece or body of knowledge. } \\
\text { Evidence is given to support the credibility of the expert and her statement. }\end{array}$ \\
\hline Scheme & From established rule \\
\hline Criteria & $\begin{array}{l}\text { The source is vague, a group of people, e.g. a community, institution, and sometimes the society as a whole who have established a specific } \\
\text { prescription. } \\
\text { The statement refers to a generalized view on what is accepted in the specific context. } \\
\text { Evidence may be used to show that the generally accepted view is truly acceptable. }\end{array}$ \\
\hline
\end{tabular}




\subsubsection{Step four}

Although we name this Step 4, it might actually be the first step the analyst takes. It refers to the cases where an argument flaw is evident without having to go through asking the critical questions. These flaws might relate to the following (Hahn, 2011; Glassner \& Schwarz, 2007): (a) circularity, in the sense of lack of consideration of different meanings or different aspects; (b) lack of challenging the relevance of the reasons invoked, which we will refer to as irrelevance; and (c) misunderstanding, which refers to using the various argumentative units in ways that do not correspond to their functions, thus revealing that the person has not understood (part of) the task. The following examples describe each one of these cases of flawed arguments.

Circularity. Two representative examples of insufficient formation of an argument are: begging the question (petitio principii) and fallacy from repetition (ad nauseam). Regarding "begging the question," it is usually the case that the reasons given for a claim are not differentiated from the claim itself, or when the reasons given to further support the main reason repeat the same thing, what Kuhn (1991) calls "pseudoevidence." The following example illustrates the second case:

Claim: Employees should not for any reason bring their pets at work.

Reason 1: This will annoy other people.

Reason 2: Pets will disturb people.

Reason 2 does not provide further support to Reason 1, as it is supposed to do. It only paraphrases the content of the main reason.

As far as repetition is concerned, it is slightly different than begging the question, as the same content is repeated among units of the "same level" of reasoning. By this, we mean that repetition does not refer to cases where the second unit is intended to further support the first unit in a subordinated manner. We rather focus on those cases in which a new statement is produced to other justify or rebut the initial claim but it fails to do so as it only repeats the initial contention. Thus, repetition is other encountered in the relation between Reason 3 and Reason 2, or in the rebuttal as it is related to the main argument. The following example illustrates the latter:

Claim: There is a high rate of divorce in the U.A.E.

Reason 1: There is no communication between the couple.

Reason 2: They don't understand each other.

Reason 3: They only believe in what they think.

Objection: Some couples understand each other.

Reason for objection: They know each other before marriage.

Rebuttal: They face problems and they may not understand each other.

Irrelevance. It mostly refers to objections or rebuttals that fail to take into consideration the relevance of the reasons supporting the initial claim. The example below shows the case of an irrelevant counter-argument:

Claim: Employees should not for any reason bring their pets at work.

Reason 1: You become less efficient.

Reason 2: You are aware of what your pet is doing.

Reason 3: Your colleagues get distracted and they work worse.

Objection: I am still more efficient than my colleagues.

Misunderstanding. Most of the time this flaw corresponds to the fallacy of self-contradiction, especially when the objection or the reason of the objection supports the same idea as the initial contention. Another case occurs when the rebuttal supports the same as the objection, instead of further supporting the initial contention, as the example shows:

Claim: Employees should not for any reason bring their pets at work.

Rebuttal: If we leave them at home they will die from loneliness. Moreover, they create a good image for the company.

\section{Findings}

In total, $1230(205 \times 6)$ units of argumentative discourse were codified using the fallacies or paralogisms described above. Regarding the coding, a high agreement (94.8\%) between two independent coders was achieved, giving a Krippendorffs Alpha of approx. 0.8, which is considered satisfying for social sciences. The few discrepancies were all solved through discussion, rendering the coding a more straightforward process than it initially seems. Of the 1230 units, 213 (17.3\%) were considered as fallacious in one of the following ways (starting from the most frequent): begging the question, repetition, incoherence, established rule, irrelevance, incompleteness, ad populum, hasty generalization, from consequence, from ignorance, ad verecundiam, slippery slope, post hoc, and false analogy.

The most common fallacies that emerged are: (a) circular reasoning (either in the form of repetition or begging the question), and (b) arguments based on some type of "false" authority (established rule or people). As far as the position of the fallacies is concerned, we observe that undergraduates' skill to construct good rebuttals is usually flawed by repetitions 
(either of the initial claim or of its reasons) and misunderstanding (students often show that they do not understand the meaning of rebuttal although it is sufficiently explained to them through examples). The other most common type of circular reasoning, i.e. begging the question, appears more often in the further backing-up efforts, and more precisely in the reason given to support the objection, and in Reason 2, which often functions subordinately to Reason 1. Finally, arguments from established rules are used in most of the cases as the primary reason participants come up with to support their claims. For a complete overview of the findings of this study, also considering the effect of variables such as culture and area of study on the quality of arguments emerged, see Rapanta and Walton (2015).

\section{Discussion}

In the study presented we showed how a simple to use argument-mapping tool can serve as a diagnostic tool regarding adult students' argumentation skills when combined with the informal logic method of identifying paraschemes. Our method is similar to how the CAS system has been used in the field of AI and law (Gordon, 2010), but adapted to education and with a tool familiar to educators. More precisely, we begin with to what the students have provided as input in the Rationale map boxes with and try to understand with the use of critical questions which scheme they are trying to apply and in what aspects it becomes a parascheme.

Although argument mapping techniques have been thoroughly used in education (e.g. van Gelder, 2005; Munneke et al., 2007), their connection with solid theories of informal logic has not been yet achieved. Given the emerging need to assist students in being able to identify informal reasoning fallacies (e.g. Neuman, 2003; Weinstock et al., 2006), the "marriage" between the paraschemes theory and a simple mapping task can serve as a thorough and handy assessment method in education. More precisely, what is new is the method proposed is a combination between the critical questions corresponding to each argumentation scheme and their application throughout the map-argument. In this way, assessment decisions made by educators regarding the level of argumentative reasoning of students can be well-structured and reasoned going through the steps described in Section 3.3. Moreover, adult students may also be assisted in improving their own reasoning process by adding this element of self-assessment through critical questions after completing a mapargument.

The scope of the paper was theoretical, as we intended to propose a method of assessment based on argument maps. However, we will also briefly discuss two of our main findings that can illustrate of the potentialities of the method proposed. The main weakness observed among the participants was the construction of rebuttals and reasons to support a possible counter-argument to their own claim. This finding is in line with other studies pointing out weak rebuttals or lack of antilogos (Glassner \& Schwarz, 2007; Kuhn et al., 2008), i.e. efficient consideration of the other party, as the main flaws of adolescent and adult reasoning. Our contribution lies on being able to explain why and where these flaws of reasoning emerge. First, with the help of a structured map, we were able to localize in which component of argumentative reasoning each weakness emerges more often; for example, begging the question was mostly found among the backing-up reasons of a counter-argument. Second, with the help of the critical questions accompanying the identification of paraschemes, we are able to make hypotheses regarding the reasons why young adults opt for more heuristic patterns of reasoning in certain cases; for example, opting for arguments from established rules was the choice of reason supporting their claim for many of the participants. The fact that the ethnical background did not play any significant role in this and other choices, as described in another study (Rapanta \& Walton, 2015) makes us think of the potential universalities that the paraschemes might have. This aspect will form part of our future work comparing argumentation patterns among different groups of participants.

Finally, one of the study's limitations that need to be considered is the fact that we were only based on students' arguments as made explicit in a structured map. It has not been made clear in this paper how the method and findings can be applied in dialogical situations, in which the critical questions may/should be asked by a partner as a way of shifting the burden of proof (Gordon et al., 2007). Nonetheless, the dialogical contextualization permitted by the combination of paraschemes with the argument mapping task suggests the potential of a model of collaborative learning, such as the ones already available in the field of AI and education (Baker, 2016), that can combine argument mapping with a dialogue framework. Future research will shed more light to the relationship between informal logic methods, AI tools, and education.

\section{References}

Andriessen, J., Erkens, G., van de Laak, C. M., Peters, N., \& Coirier, P. (2003). Argumentation as negotiation in computer supported collaborative writing. In J. Andriessen, M. Baker, \& D. Suthers (Eds.), Arguing to learn: confronting cognitions in computer-supported collaborative learning environments (pp. 79-116). Dordrecht: Kluwer.

Asterhan, C. S. C., \& Schwarz, B. B. (2009). Argumentation and explanation in conceptual change: Indications from protocol analyses of peer-to-peer dialog. Cognitive Science, 33(3), 374-400. http://dx.doi.org/10.1111/j.1551-6709.2009.01017.x.

Baker, M. J. (2009). Argumentative interactions and the social construction of knowledge. In N. M. Mirza, \& A.-N. Perret-Clermont (Eds.), Argumentation and education: Theoretical foundations and practices (pp. 127-144).Berlin: Springer-Verlag.

Baker, M. J. (2016). The negotiation of meaning in epistemic situations. International Journal of Artificial Intelligence in Education, 26(1), 133-149. http://dx.doi. org/10.1007/s40593-015-0050-3.

Berland, L. K., \& Reiser, B. J. (2009). Making sense of argumentation and explanation. Science Education, 93(1), 26-55. http://dx.doi.org/10.1002/sce.20286. Danziger, J. (1985). Social science and the social impacts of computer technology. Social Science Quarterly, 66(1), 3-21.

Dwyer, C. P., Hogan, M. J., \& Stewart, I. (2013). An examination of the effects of argument mapping on students' memory and comprehension performance. Thinking Skills and Creativity, 8, 11-24. http://dx.doi.org/10.1016/j.tsc.2012.12.002.

Gigerenzer, G., Todd, P. M., \& The ABC Research Group (1999). Simple heuristics that make us smart. Oxford, UK: Oxford University Press. 
Glassner, A., \& Schwarz, B. B. (2007). What stands and develops between creative and critical thinking? Argumentation?. Thinking Skills and Creativity, 2(1), 10-18. http://dx.doi.org/10.1016/j.tsc.2006.10.001.

Goodwin, W. (2010). The 'passes-for'fallacy and the future of critical thinking. Argumentation, 24(3), 363-374. http://dx.doi.org/10.1007/s10503-009-9170-y.

Gordon, T. F. (2010). An overview of the Carneades argumentation support system. In C. W. Tindale, \& C. Reed (Eds.), Dialectics, dialogue and argumentation. An examination of Douglas Waltons theories of reasoning (pp. 145-156).London, UK: College Publications.

Gordon, T. F., Prakken, H., \& Walton, D. (2007). The Carneades model of argument and burden of proof. Artificial Intelligence, 171(10), 875-896. http://dx.doi. org/10.1016/j.artint.2007.04.010.

Klaczynski, P. A. (2001). Analytic and heuristic processing influences on adolescent reasoning and decision-making. Child development, 72(3), 844-861. http://dx.doi.org/10.1111/1467-8624.00319.

Kuhn, D. (1991). The skills of argument. Cambridge: Cambridge University Press.

Kuhn, D., Goh, W., Iordanou, K., \& Schaenfield, D. (2008). Arguing on computer: a microgenetic study of developing argument skills in a computer-supported environment. Child development, 79(5), 1310-1328. http://dx.doi.org/10.1111/j.1467-8624.2008.01190.x.

Maloney, J., \& Simon, S. (2006). Mapping children's discussions of evidence in science to assess collaboration and argumentation. International Journal of Science Education, 28(15), 1817-1841. http://dx.doi.org/10.1080/09500690600855419.

Marttunen, M., \& Laurinen, L. (2007). Collaborative learning through chat discussions and argument diagrams in secondary school. Journal of Research on Technology in Education, 40(1), 109-126. http://dx.doi.org/10.1080/15391523.2007.10782500.

Munneke, L., Andriessen, J., Kanselaar, G., \& Kirschner, P. (2007). Supporting interactive argumentation: influence of representational tools on discussing a wicked problem. Computers in Human Behavior, 23(3), 1072-1088. http://dx.doi.org/10.1016/j.chb.2006.10.003.

Neuman, Y. (2003). Go ahead, prove that God does not exist! On high school students' ability to deal with fallacious arguments. Learning and Instruction, 13 (4), 367-380. http://dx.doi.org/10.1016/S0959-4752(02) 00011-7.

Nussbaum, E. M. (2011). Argumentation, dialogue theory, and probability modeling: alternative frameworks for argumentation research in education. Educational Psychologist, 46(2), 84-106. http://dx.doi.org/10.1080/00461520.2011.558816.

Okada, A., \& Buckingham Shum, S. (2008). Evidence-based dialogue maps as a research tool to evaluate the quality of school pupils' scientific argumentation. International Journal of Research and Method in Education, 31(1), 291-315. http://dx.doi.org/10.1080/17437270802417184.

Pinkwart, N., Lynch, C., Ashley, K., \& Aleven, V. (2008). Re-evaluating LARGO in the classroom: Are diagrams better than text for teaching argumentation skills? Intelligent Tutoring Systems., 5091, 90-100. http://dx.doi.org/10.1007/978-3-540-69132-7_14.

Rapanta, C., \& Walton, D. (2015). Identifying paralogisms in two ethnically different contexts at university level. Infancia y Aprendizaje: Journal for the Study of Education and Development [Online first].. http://dx.doi.org/10.1080/02103702.2015.1111610.

Reed, C., \& Rowe, G. (2004). Araucaria: Software for argument analysis, diagramming and representation. International Journal on Artificial Intelligence Tools, 13(4), 961-979. http://dx.doi.org/10.1142/S0218213004001922.

Reed, C., Walton, D., \& Macagno, F. (2007). Argument diagramming in logic, law and artificial intelligence. The Knowledge Engineering Review, 22(1), 87-109. http://dx.doi.org/10.1017/S0269888907001051.

Scheuer, O., Loll, F., Pinkwart, N., \& McLaren, B. M. (2010). Computer-supported argumentation: a review of the state of the art. International Journal of Computer-Supported Collaborative Learning, 5(1), 43-102. http://dx.doi.org/10.1007/s11412-009-9080-x.

Scheuer, O., McLaren, B. M., Weinberger, A., \& Niebhur, S. (2014). Promoting critical, elaborative discussions through a collaboration script and argument diagrams. Instructional Science, 42(2), 127-157. http://dx.doi.org/10.1007/s11251-013-9274-5.

Stake, R. (1995). The art of case research. Newbury Park, CA: Sage Publications.

Suthers, D. D. (2003). Representational guidance for collaborative inquiry. In J. Andriessen, \& al. et (Eds.), Arguing to learn: confronting cognitions in computersupported collaborative learning environments (pp. 27-46).Dordrecht: Kluwer.

Tellis, W. M. (1997). Application of a case study methodology. The qualitative report, 3(3), 1-19 Retrieved on December 18, 2015 from: http://nsuworks.nova. edu/cgi/viewcontent.cgi? article=2015\&context=tqr.

Toth, E. E., Suthers, D. D., \& Lesgold, A. M. (2002). Mapping to know: The effects of representational guidance and reflective assessment on scientific inquiry. Science Education, 86(2), 264-286 Retrieved online on September 15, 2015 from: http://onlinelibrary.wiley.com/store/10.1002/sce.10004/asset/ 10004_ftp.pdf?v=1\&t=ijcpig30\&s=6dd00fde1cac6abe97da222d59f93a19c49a69c7.

Twardy, C. (2004). Argument maps improve critical thinking. Teaching Philosophy, 27(2), 95-116. http://dx.doi.org/10.5840/teachphil200427213.

van Amelsvoort, M., Andriessen, J., \& Kanselaar, G. (2007). Representational tools in computer-supported collaborative argumentation-based learning: how dyads work with constructed and inspected argumentative diagrams. The Journal of the Learning Sciences, 16(4), 485-521. http://dx.doi.org/10.1080/ 10508400701524785.

van Gelder, T. (2005). Teaching critical thinking: some lessons from cognitive science. College Teaching, 53(1), 41-48. http://dx.doi.org/10.3200/ CTCH.53.1.41-48.

van Gelder, T. (2007). The rationale for Rationale ${ }^{\mathrm{TM}}$. Law, Probability and Risk, 6, 23-42. http://dx.doi.org/10.1093/lpr/mgm032.

Walton, D. N. (2010). Why fallacies appear to be better arguments than they are. Informal Logic, 30(2), 159-184.

Walton, D. N. (2011a). Defeasible reasoning and informal fallacies. Synthese, 179(3), 377-407.

Walton, D. N. (2011b). Argument mining by applying argumentation schemes. Studies in Logic, 4(1), 38-64.

Weinstock, M. P., Neuman, Y., \& Glassner, A. (2006). Identification of informal reasoning fallacies as a function of epistemological level, grade level, and cognitive ability. Journal of Educational Psychology, 98(2), 327-341. http://dx.doi.org/10.1037/0022-0663.89.2.327.

Yin, R. (1994). Case study research: design and methods, 2nd ed. Thousand Oaks, CA: Sage Publishing. 